\title{
What Factors Explain Bicycling and Walking for Commuting by ELSA-Brasil Participants?
}

\author{
Sheila Maria Alvim de Matos, PhD', Francisco José Gondim Pitanga, PhD', \\ Maria da Conceição C. Almeida, $\mathbf{P h D}^{3}$, Ciro Oliveira Queiroz, $\mathbf{M S c}^{4}$, \\ Clarice Alves dos Santos, MSc ${ }^{1,5}$, Rogerio Tosta de Almeida, PhD ${ }^{1,6}$, \\ lanne Tayrine Martins da Silva, BSc', Rosane Harter Griep, PhD $^{7}$, \\ Leila Denise Alves Ferreira Amorim, $\mathrm{DrPH}^{8}$, Ana Luísa Patrão, $\mathrm{PhD}^{\prime}$, and \\ Estela M. L. Aquino, PhD'
}

\begin{abstract}
Purpose: To analyze the factors associated with commuting by bicycling and walking in adult participants from ELSA-Brasil (Longitudinal Study of Adult Health).

Design: Cross-sectional.

Setting: Six teaching/research institutions throughout Brazil.

Participants: A total of 15105 civil servants.

Measures: Commuting by bicycling and walking was analyzed using the long-form International Physical Activity Questionnaire.

Analysis: A hierarchical model containing possible factors associated with commuting by bicycling and walking was constructed. Crude and adjusted odds ratios were calculated using multinomial logistic regression.

Results: Considering the 2 forms of commuting, $66 \%$ of the participants were being considered inactive or insufficiently active. In women, being "heavier," feeling unsafe practicing physical activity, and being a former smoker were factors negatively associated with commuting by bicycling and walking. In men, active commuting was less common among those who were overweight or had abdominal obesity, those with a negative perception of safety, and those reporting that there was nowhere suitable in the neighborhood to practice physical activity.
\end{abstract}

Conclusion: Obesity and negative perceptions in the neighborhood are associated with inactive or insufficiently active commuting. The relevance of this finding for public health is reinforce developing policies aimed at promoting health in Brazil and in other countries with similar characteristics.

\section{Keywords}

cycling, walking, commuting, physical activity, social inequalities in health

\section{Purpose}

Commuting physical activity in the form of walking or bicycling is encouraged in various regions of the world as a healthy behavior. ${ }^{1,2}$ Despite this evidence, commuting by walking and, principally, cycling, is not the norm, either in countries with a high socioeconomic level ${ }^{3,4}$ or in those with intermediate to low economic levels. ${ }^{5,6}$ A recent study conducted in Brazil found that only $33.4 \%$ of adults and $26.1 \%$ of the elderly population evaluated participated in active commuting $(\geq 150 \mathrm{~min} /$ wk), showing that cycling or walking as a form of commuting is unusual, with consequently few positive repercussions on collective health. ${ }^{7}$

Identifying the factors associated with commuting physical activity (cycling and walking) may be relevant when developing strategies to encourage this behavior in the general

\footnotetext{
'Institute of Collective Health, Federal University of Bahia (UFBA), Salvador, Bahia, Brazil

${ }^{2}$ Department of Physical Education, School of Education, Federal University of Bahia (UFBA), Salvador, Bahia, Brazil

${ }^{3}$ Institute Gonçalo Moniz, Oswaldo Cruz Foundation, Bahia, Brazil

${ }^{4}$ Bahia School of Medicine and Public Health, Salvador, Bahia, Brazil

${ }^{5}$ Department of Biological Sciences, State University of Southwestern Bahia (UESB), Jequié, Bahia, Brazil

${ }^{6}$ Department of Health, State University of Feira de Santana (UEFS), Feira de Santana, Bahia, Brazil

${ }^{7}$ Laboratory of Education in Environment and Health, Oswaldo Cruz Institute, Oswaldo Cruz Foundation, Rio de Janeiro, Brazil

${ }^{8}$ Department of Statistics, Institute of Mathematics and Statistics, Federal University of Bahia (UFBA), Salvador, Bahia, Brazil
}

\section{Corresponding Author:}

Sheila Maria Alvim de Matos, Institute of Collective Health, Federal University of Bahia (UFBA), Rua Basilio da Gama, s/n, Campus Universitário Canela, Salvador, Bahia, 40I 10040, Brazil.

Email: salvim@ufba.br 
population. In another recent study conducted in Curitiba, Brazil, $11.2 \%$ of participants commuted by bicycle, with this habit being more common among men, among those of 30 to 39.9 years of age, those with a poor socioeconomic level, among bicycle owners, and those with a negative perception of their quality of life. ${ }^{8}$

The environmental characteristics that may facilitate or deter active commuting ${ }^{9}$ depend on the urban design, that is, the physical configuration of the environment (connectivity and proximity), the use of the land in terms of density and diversity, and the quality of urban conditions. ${ }^{10}$ Studies conducted in high-income countries have shown a positive association between walkability and physical activity. Barcelona, for instance, is a city with a compact urban environment, diversity with respect to land use, a high density of bus stops, and good coverage of public transportation $(47.3 \%)$ in relation to private transportation $(22.17 \%){ }^{11}$

Individual and socioeconomic factors may also influence the promotion of commuting by bicycling and walking. Individual factors such as chronic morbidities and excess weight or obesity negatively affect active commuting. ${ }^{12}$ Studies conducted in Brazil focusing on socioeconomic factors showed that women who were older, with higher income levels, and with better education levels were more likely to be inactive with respect to commuting by bicycling and walking than men with the same characteristics. ${ }^{13-15}$

The marked social inequalities that characterize Brazil are also reflected in urban mobility, since they affect the choice of and access to means of public transportation, as well as where individuals live. ${ }^{16}$ The housing policy in the country has reinforced spatial segregation, resulting in the poor segments of the population living in areas on the outskirts of cities where public services, including public transportation, are negligible. Therefore, belonging to the poorest segments of society means living in areas not serviced by public transport and having to walk long distances from home to a bus stop and then from a bus stop to the individual's destination that is usually their workplace. ${ }^{17}$

In this context, the contributions of the International Physical Activity Environment Network studies carried out in several areas of the world, including Brazil, stand out. Recent publication of this research group has shown that living in more densely populated areas, having a well-connected street network, more diverse land uses, and having more parks were positively associated with transport-related walking and/or cycling. ${ }^{18}$

In Brazilian cities, the higher an individual's socioeconomic level, the greater his or her mobility in terms of being able to cover greater distances in less time. This is particularly true in the case of the privileged upper classes of society who own automobiles. ${ }^{16}$ A recent study carried out in Brazil showed an inverse association between family income and active commuting with gross family income acting as moderator of this association. $^{19}$

A considerable part of the literature published on physical activity and sedentariness originates in developed countries. ${ }^{20}$ The identification of factors associated with commuting bicycling and walking in a developing country, through the use of demographic, social, environmental, behavioral, and biological determinants, is relevant to the international debate and should provide subsidies for public policies aimed at encouraging active commuting in countries with similar characteristics to those of Brazil. Such initiatives could contribute toward preventing various metabolic and cardiovascular disorders, consequently reducing costs to the health-care system. ${ }^{21}$ Participants of the ELSA-Brasil cohort (Longitudinal Study of Adult Health) ${ }^{21,22}$ with better perceived conditions for walking in neighborhoods were more active. This highlights the importance of actions within the context of cities for the development of healthy habits. ${ }^{17}$ The purpose of the study was to evaluate the associated factors with commuting by bicycling and walking in Brazilian adults.

\section{Methods}

\section{Sample}

The sample for the Brazilian Longitudinal Study of Adult Health-ELSA-Brasil consisted of 15105 volunteers, active and retired civil servants of 35 to 74 years of age at the time of recruitment from 6 institutions of higher education situated in the Brazilian cities of Salvador, Vitória, Belo Horizonte, Rio de Janeiro, São Paulo, and Porto Alegre. The participants were proportionally distributed across the 6 centers according to their eligibility. For a better distribution, recruitment goals were defined by sex, age, and occupational category. A statistical power analysis was conducted to determine an adequate sample size, and the size estimation was based on the main study outcomes. More details of the study methodology have already been published elsewhere. ${ }^{21,22}$

\section{Design}

The ELSA-Brasil is a multicenter cohort study. In the present study, all the individuals who participated in the baseline (2008-2010) assessment and who provided information on physical activity and on their social, physical, and individual environments were included in the analysis, a total of 14876 participants, with an exclusion rate of $1.5 \%$.

The institutional internal review boards of all the 6 research centers involved approved the ELSA-Brasil study protocol. All the participants signed an informed consent form. The confidentiality of participants' data was guaranteed, and their identity was concealed.

\section{Measures}

Data were collected by a team of trained interviewers and assessors, and certified by a quality control board capable of applying the study protocol in any ELSA-Brasil research center. ${ }^{21}$ The study included face-to-face interviews to complete the questionnaires and to measure weight, height, and waist circumference. All participants, active or retired, were asked about their current and first jobs. If retired, they were asked about their first and last jobs. ${ }^{22}$ 
The context of the neighborhood was defined based on selfreported evaluations. ${ }^{17,23}$ The variables of interest were those referring to traffic conditions, individuals' perceptions of their own safety when practicing physical activity, violence in the neighborhood, and conditions and opportunities for physical activity, including active commuting. The participants were asked questions such as "Is traffic heavy in your neighborhood?"; "Do you feel safe walking during the day and at night in your neighborhood?"; "Does your neighborhood provide facilities for people to be physically active (walking, biking)?" and "Are there many opportunities to practice physical activities or sports in clubs, gyms or other spaces in your neighborhood?". Negative answers were coded as 0 and positive answers as 1 .

Participants were weighed barefoot and wearing only a patient gown in the morning after an 8- to 12-hour fast. Weight was measured using a Toledo ${ }^{\circledR}$ electronic scale with a maximum capacity of $200 \mathrm{~kg}$. A $\mathrm{SECA}^{\circledR}$ stadiometer was used to measure height, with the participant barefoot and standing straight, with their back to the stadiometer, heels together and toes apart at a $45^{\circ}$ angle, and head in the Frankfort horizontal plane. Waist circumference was measured using a nonelastic tape at the midpoint between the lower rib and the iliac crest on the right side, or, if impossible to determine, at the umbilicus. Hip circumference was measured loosely at the level of the maximum protrusion of the gluteal muscles (hip), over the participant's gown, using a nonelastic, flexible measuring tape. ${ }^{24}$ Standards and recommended technical criteria were observed at all stages in the anthropometric evaluation. The equipment was installed and calibrated in all the study centers in accordance with standardized procedures.

The long-form International Physical Activity Questionnaire (IPAQ) was used to identify and quantify physical activity. The IPAQ is made up of questions on the frequency and duration of physical activity (moderate and vigorous walking) carried out at work, in commuting, in housework, and during leisure time. ${ }^{25}$ In this study, only the commuting physical activity domain was used. Commuting by bicycling and walking was measured in minutes per week by multiplying the weekly frequency by the duration of each one of the activities performed. Participants were asked about their move from one place to another with the following questions: (1) how many days a week do you use the bike to get from one place to another? (2) on these days, how much time in total you pedal per day? (3) how many days a week do you walk to go from place to place? (4) in those days, how much time in total you walk in a day? The results were classified into $0=$ inactive $(<10 \mathrm{~min} / \mathrm{wk}), 1=$ insufficiently active $(10$ 149 minutes per week spent in walking and/or cycling), and $2=$ physically active ( $\geq 150$ minutes per week spent in walking and/ or cycling). ${ }^{26}$

\section{Analysis}

Latent class analysis (LCA) was used to elucidate the social and anthropometric constructs. Latent class analysis describes unobserved characteristics by modeling the observed response patterns of variables that capture the behavior of the construct of interest. Latent class analysis is used to determine mutually exclusive groups and assumes conditional independence. We estimated 2 parameters for each latent variable using LCA: (1) class prevalence, which measured the proportion of individuals assigned to each latent class and (2) the conditional probabilities, that is, the response patterns of the observed variables in a given latent class. $^{27}$

The optimal number of classes to characterize the data is selected in LCA based on different strategies, including an interpretation of the estimated conditional probabilities or using Akaike Information Criteria, ${ }^{28}$ the Schwarz Bayesian Information Criterion (BIC), the sample-size-adjusted $\mathrm{BIC},{ }^{29,30}$ the Lo-Mendell-Rubin likelihood ratio test, and bootstrap likelihood ratio test. A measure of model quality is entropy, which is related to a posteriori classification uncertainty. Entropy values close to 1 indicate highly discriminatory classes. ${ }^{31}$ The conditional independence assumption was evaluated using bivariate residuals. Participants were classified according to their most likely latent class membership.

Participants' anthropometric profile was classified using a construct that encompassed the variables: body mass index, abdominal obesity, and waist-to-hip ratio, according to the conditional probabilities in the LCA model. The 2-class latent variable was "slimmer" or "heavier." Likewise, to define the socioeconomic levels "low," "intermediate," and "high," a 3class LCA model was constructed based on the variables reported by participants: education level, income, social class, and intergenerational social mobility.

In addition to the anthropometric and socioeconomic constructs and the variables regarding the neighborhood, other factors associated with commuting physical activity that were analyzed included age, self-reported skin color/ethnicity, smoking, and whether the participant provided care for sick or dependent family members.

Commuting by bicycling and walking was the dependent variables, whereas the independent variables were grouped into blocks: distal block (latent variable for socioeconomic level), intermediate block (traffic conditions for the practice of physical activity, the participant's perception of safety for the practice of physical activity, the participant's perception of violence in the neighborhood, and the conditions and opportunities for the practice of physical activity), and the proximal block (latent variable for anthropometric status, smoking, age, self-reported skin color/ethnicity, and whether the participant cared for sick or dependent family members; Figure 1). ${ }^{32}$

All analyses were stratified by gender since there is an accumulation of evidence in the scientific literature, ${ }^{33}$ showing differences between males and females regarding their use of work and leisure time that influence decisions in the organization of daily life and, consequently, in physical activity in its various domains.

Crude and adjusted odds ratios were estimated together with their $95 \%$ confidence intervals using multinomial logistic regression, taking as a reference the classification inactive with 


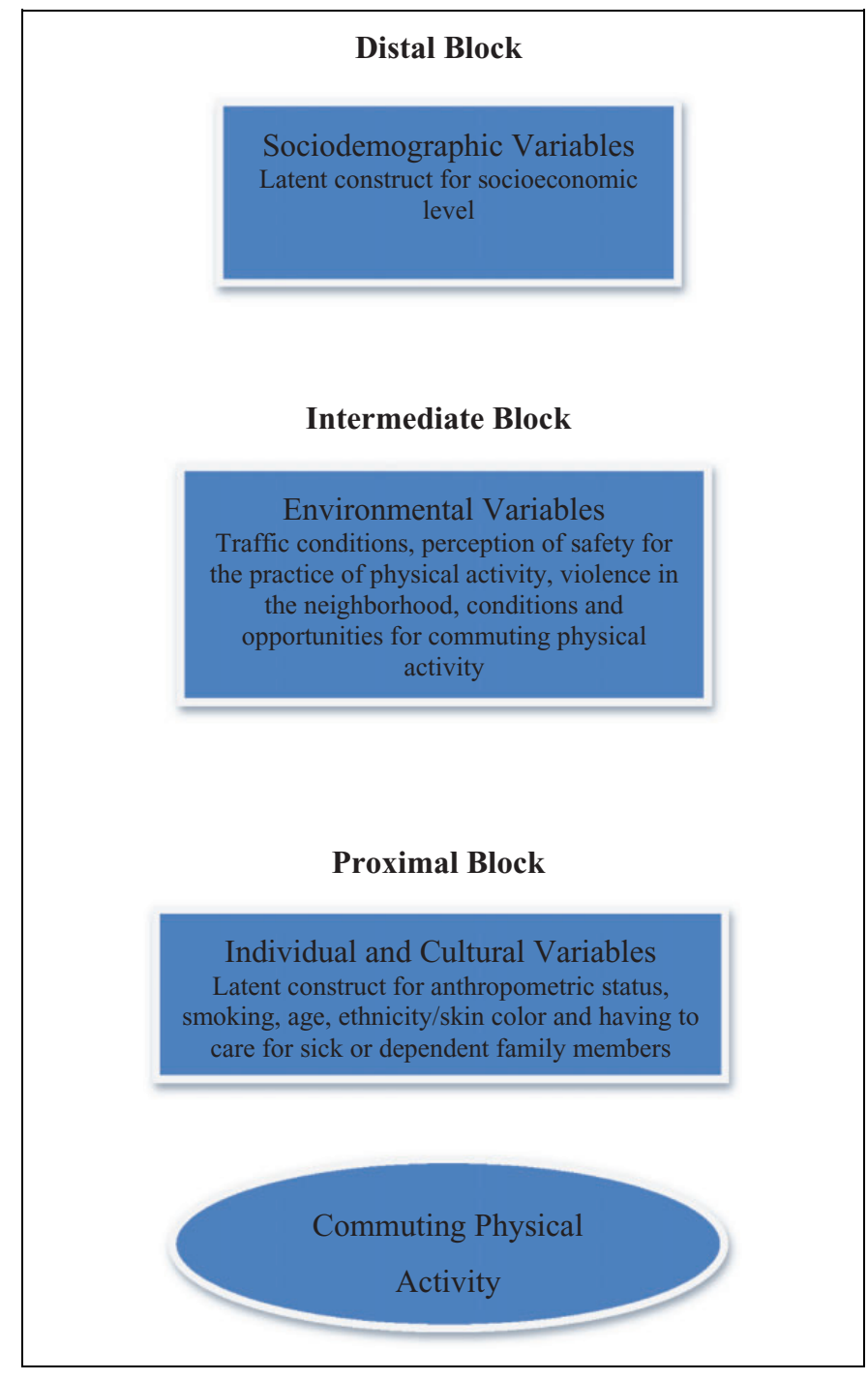

Figure I. Multivariate hierarchical model used to analyze the factors associated with commuting physical activity in adult participants of the ELSA-Brasil. Adapted from Pitanga et al. ${ }^{32}$

respect to commuting physical activity to discriminate against potential-associated factors of hierarchical levels (Figure 1). The strategy used for the entry of variable blocks was the forward stepwise method, in the following order: distal block, intermediate block, and proximal block. In the steps of the hierarchical analysis, variables with $P$ values $<.1$ remained in the model. The statistical software program STATA, version 12.0, and MPlul, version 7.3 were used throughout the statistical analysis.

\section{Results}

Cycling was reported by $4.3 \%$ of the participants, with less than $2 \%$ reporting the use of a bicycle for more than $150 \mathrm{~min} / \mathrm{wk}$. A larger proportion of the participants reported walking as a commuting physical activity, with $32.7 \%$ being considered active, $39.3 \%$ insufficiently active, and $28 \%$ inactive. Considering the 2 forms of commuting physical activities, $34 \%$ of the participants cycled and/or walked for more than $150 \mathrm{~min} / \mathrm{wk}$, with men being slightly more active than women $(36.1 \%$ and $32.2 \%$, respectively; Table 1 ). The main criteria for the choice of the LCA models were the interpretation of the estimated conditional probabilities, the entropy and the probabilities of error classification. The entropies for the 2-class LCA model for anthropometric status were 1.000 and 0.987 , respectively, for women and men. The corresponding entropies for the 3class LCA model for socioeconomic level were 0.838 and 0.843 . Detailed results for the selected LCA models for anthropometric status and socioeconomic levels are available as supplemental material.

In the hierarchical multinomial logistic regression model for the women, the least active in commuting compared to inactive (the reference category) or insufficiently active, were those classified as having a less favorable anthropometric status, that is, the "heavier" participants, those who did not feel safe practicing physical activity and former smokers. The most active women tended to be older, to have poorer socioeconomic levels, to describe their ethnicity as black or indigenous, and to describe traffic in their neighborhood as heavy (Table 2).

Overweight men and those with excess abdominal obesity, those with a negative perception regarding safety, and those reporting a lack of suitable conditions for the practice of physical activity in the neighborhood were the least active in commuting as compared to the inactive (reference) and insufficiently active groups. The most active participants were those with poorer socioeconomic levels, those who described themselves as black, those who reported traffic in the neighborhood as being heavy, those who perceived their neighborhood as being violent, and those who reported having to care for sick or dependent relatives in the home and older participants. Participation in commuting physical activity tended to increase with age (Table 3 ).

\section{Discussion}

In the present study, $34 \%$ of the participants walked or cycled to work for a minimum of 150 minutes per week. Other studies have reported that men tend to be more physically active in the domains of leisure, commuting, and occupational activities, whereas women are more active in the domestic domain, ${ }^{13}$ which may be explained by the different gender roles and by the unequal division of family labor. In Brazil, as in many countries, women undertake a double workload and are obliged to divide their time between their professional and domestic lives, with implications in task prioritization. ${ }^{34}$

Men and women from lower socioeconomic strata tended to participate more in commuting by bicycling and walking. This finding reinforces the idea that this is the result of social inequalities in urban mobility rather than the adoption of a healthy habit. ${ }^{19}$ For the less privileged commuting, which is often difficult, partially because of the poor road surfaces of the less affluent neighborhoods, represents an accumulation of difficulties with respect to the access of these individuals to public services. ${ }^{16}$ On the other hand, the poor quality of public 
Table I. Characteristics of the Study Population According to Sex. ${ }^{a}$

\begin{tabular}{|c|c|c|c|c|}
\hline \multirow[b]{2}{*}{ Characteristics } & \multicolumn{2}{|c|}{$\begin{array}{l}\text { Women, } \\
\mathrm{n}=8.218\end{array}$} & \multicolumn{2}{|c|}{$\begin{array}{c}\text { Men, } \\
\mathrm{n}=6.887\end{array}$} \\
\hline & $\mathrm{n}$ & $\%$ & $\mathrm{n}$ & $\%$ \\
\hline \multicolumn{5}{|l|}{ Commuting: bicycling and walking } \\
\hline Active & 2648 & 32.2 & 2486 & 36.1 \\
\hline Insufficiently active & 3203 & 39.0 & 2656 & 38.6 \\
\hline Inactive & 2367 & 28.8 & 1745 & 25.3 \\
\hline \multicolumn{5}{|l|}{ Latent variable for socioeconomic level } \\
\hline High & 2684 & 32.7 & 2786 & 40.5 \\
\hline Intermediate & 1985 & 24.1 & 1372 & 19.9 \\
\hline Low & 3549 & 43.2 & 2729 & 39.6 \\
\hline \multicolumn{5}{|l|}{ Traffic in the neighborhood } \\
\hline Not heavy & 2231 & 51.5 & 2099 & 48.5 \\
\hline Heavy & 5805 & 56.1 & 4546 & 43.9 \\
\hline Neutral & 182 & 42.9 & 242 & 57.1 \\
\hline \multicolumn{5}{|l|}{ Safety for the practice of physical activity } \\
\hline Feels safe & 4996 & 52.2 & 4571 & 47.8 \\
\hline Does not feel safe & 2945 & 59.7 & 1989 & 40.3 \\
\hline Neutral & 277 & 45.9 & 327 & 54.1 \\
\hline \multicolumn{5}{|l|}{$\begin{array}{l}\text { Violence in the neighborhood for the } \\
\text { practice of physical activity }\end{array}$} \\
\hline Violence is not a problem & 3176 & 53.7 & 2733 & 46.3 \\
\hline Violence is a problem & 4519 & 55.3 & 3653 & 44.7 \\
\hline Neutral & 523 & 51.1 & 501 & 48.9 \\
\hline \multicolumn{5}{|l|}{$\begin{array}{l}\text { Are conditions in the neighborhood } \\
\text { adequate for walking and bicycling? }\end{array}$} \\
\hline Yes & 5480 & 53.4 & 4775 & 46.6 \\
\hline No & 2318 & 57.3 & $|73|$ & 42.7 \\
\hline Neutral & 420 & 52.4 & 381 & 47.6 \\
\hline \multicolumn{5}{|c|}{$\begin{array}{l}\text { Opportunities in the neighborhood for the } \\
\text { practice of physical activity }\end{array}$} \\
\hline Yes & 6000 & 54.6 & 4989 & 45.4 \\
\hline No & 2001 & 54.3 & 1683 & 45.7 \\
\hline Neutral & 217 & 50.23 & 215 & 49.8 \\
\hline \multicolumn{5}{|l|}{ Latent variable for anthropometric status } \\
\hline Normal & 4574 & 55.7 & 5101 & 74.1 \\
\hline Overweight and abdominal obesity & 3644 & 44.3 & 1786 & 25.9 \\
\hline \multicolumn{5}{|l|}{ Smoking } \\
\hline Never smoked & 5128 & 59.7 & 3466 & 40.3 \\
\hline Former smoker & 2097 & 46.3 & 2436 & 53.7 \\
\hline Smoker & 993 & 50.2 & 984 & 49.8 \\
\hline \multicolumn{5}{|l|}{ Age } \\
\hline 35 to 44 years & 1779 & 53.3 & $|56|$ & 46.7 \\
\hline 45 to 54 years & 3256 & 54.8 & 2683 & 45.2 \\
\hline 55 to 64 years & 2379 & 56.2 & 1855 & 43.8 \\
\hline 65 to 74 years & 804 & 50.5 & 788 & 49.5 \\
\hline \multicolumn{5}{|l|}{ Self-reported ethnicity/skin color } \\
\hline White & 4192 & 53.8 & 3599 & 46.2 \\
\hline Black & 1456 & 60.7 & 941 & 39.3 \\
\hline Brown & 2175 & 51.8 & 2027 & 48.2 \\
\hline Yellow & 246 & 65.8 & 128 & 34.2 \\
\hline Indigenous & 65 & 41.4 & 92 & 58.6 \\
\hline \multicolumn{5}{|l|}{$\begin{array}{l}\text { Cares for sick or dependent family } \\
\text { members }\end{array}$} \\
\hline No & 7328 & 53.8 & 6296 & 46.2 \\
\hline Yes & 880 & 60.2 & 582 & 39.8 \\
\hline
\end{tabular}

${ }^{a}$ ELSA-Brasil, 2008 to 2010.

transportation affects the choice of those who make up the more privileged social classes to commute by car.

Also in ELSA-Brasil, the privileged social classes are predominantly white, and this interpretation is reinforced by the finding that the female participants of the ELSA-Brasil who reported their ethnicity/skin color as black or indigenous and the male participants who reported their ethnicity/skin color as black were associated with a greater likelihood of participating in commuting physical activity. This finding differs from the findings of studies conducted in the United States, showing whites to be more active in commuting physical activity. ${ }^{34,35}$ In Brazil, the black population has historically had more social inequalities insofar as their access to goods and services, including housing and public transportation, is concerned. The socioeconomic inequalities are compounded by racism and by discrimination regarding access to the labor market and housing, which may explain the independent effect of ethnicity/skin color even after adjustment at the socioeconomic level. This finding merits further investigation.

In the ELSA-Brasil cohort, the individuals tended to participate more in commuting by bicycling and walking as they aged. Recently published data from the ELSA-Brasil ${ }^{32}$ have already shown that both age in women and the state of being retired for both sexes increase the practice of leisure-time physical activity. Benedetti et $\mathrm{al}^{36}$ reported that $59.3 \%$ of the elderly population maintained the same characteristics of physical activity both in their free time and in commuting physical activity. It is assumed that retired individuals have more free time available for both leisure time activities and commuting physical activity.

In the present study, the individuals who perceived the traffic in their neighborhood as heavier participated more in commuting by bicycling and walking, whereas those who perceived their neighborhood as unsafe, on the other hand, were less likely to participate in commuting physical activity. Conflicting results were found in a study conducted in the state of Bahia in which lack of safety during the practice of physical activity and the perception of danger/violence in the neighborhood had no effect on behavior in relation to commuting bicycling and walking. ${ }^{37}$ In fact, few studies have dealt with the association between perceptions of violence/policing and physical activity, taking into consideration that areas in which policing is more intense may provide a greater sensation of safety and consequently increase the possibility that residents will practice physical activity.

Women who were former smokers were less likely to be active in commuting. An interfering factor here is the weight gain commonly associated with stopping smoking that contributes to low levels of physical activity. ${ }^{36}$ Smokers are more likely to be sedentary, since their capacity to perform physical activity may be reduced due to physiological alterations and the development of diseases that hamper the practice of physical activity.

A paradoxical finding of the present study was the positive association between caring for sick or dependent family members and an increase in commuting by bicycling and walking in men alone. Women were more likely to report this type of responsibility; however, it had no effect on the amount of physical activity they performed. The type of support provided is unknown and may range from helping with personal hygiene 


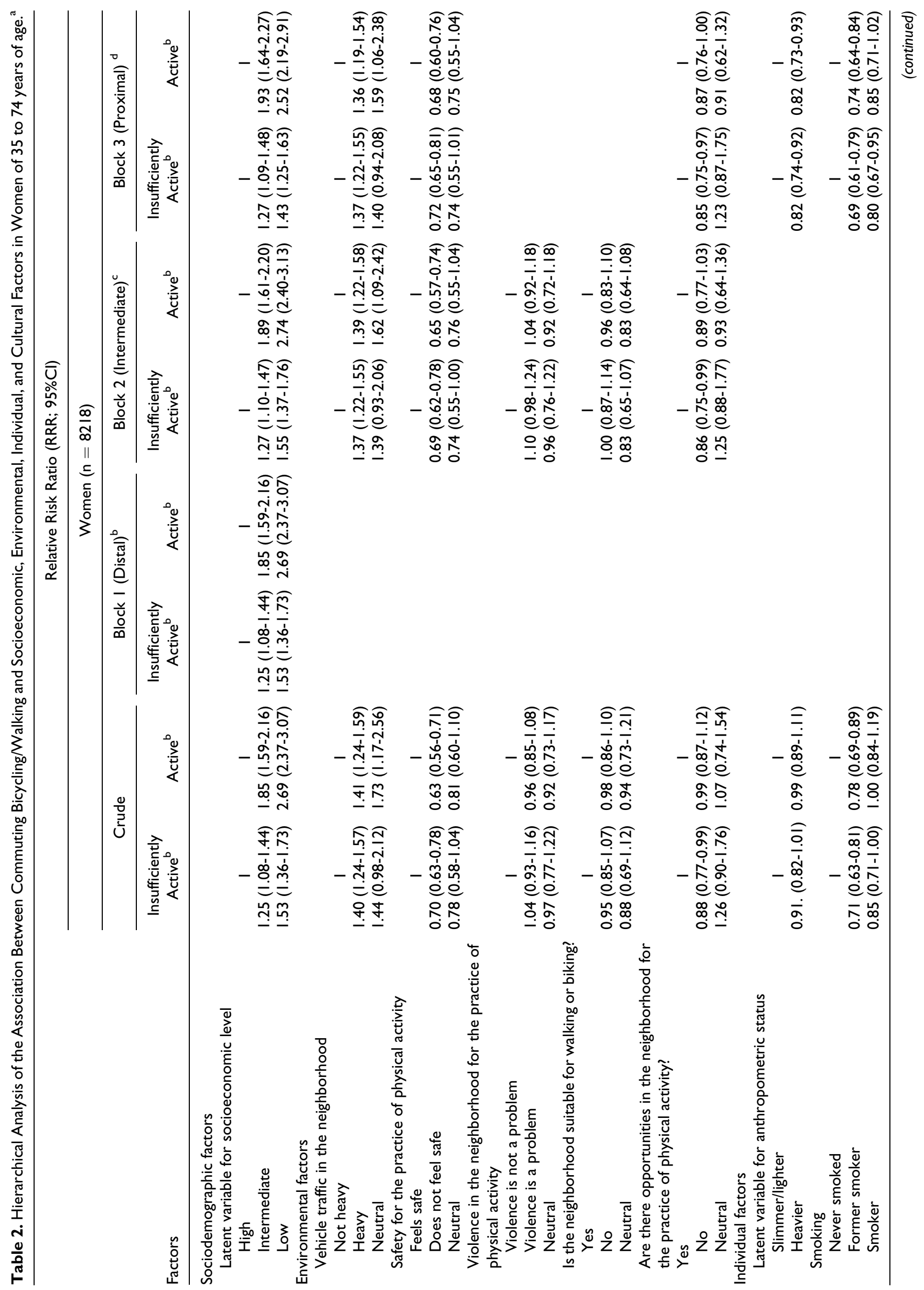




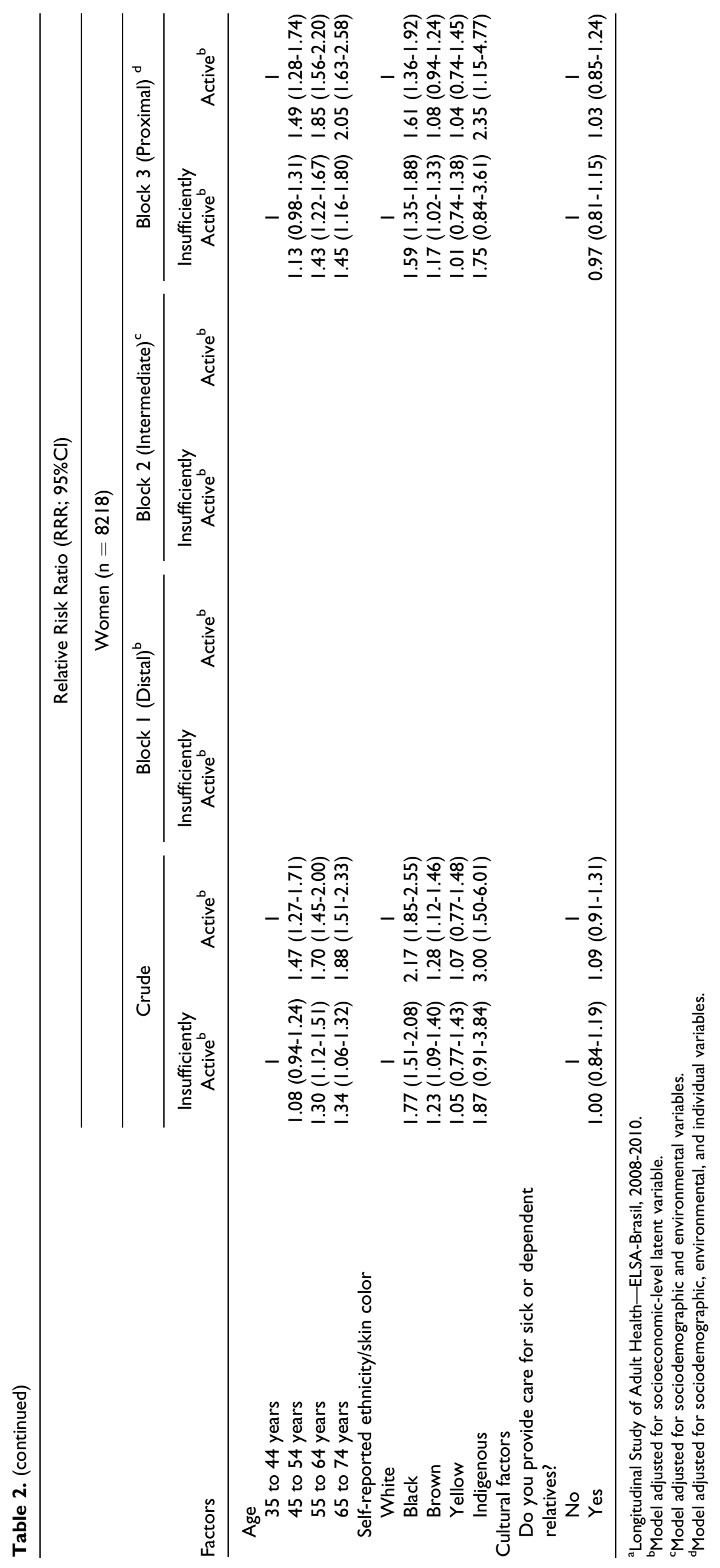




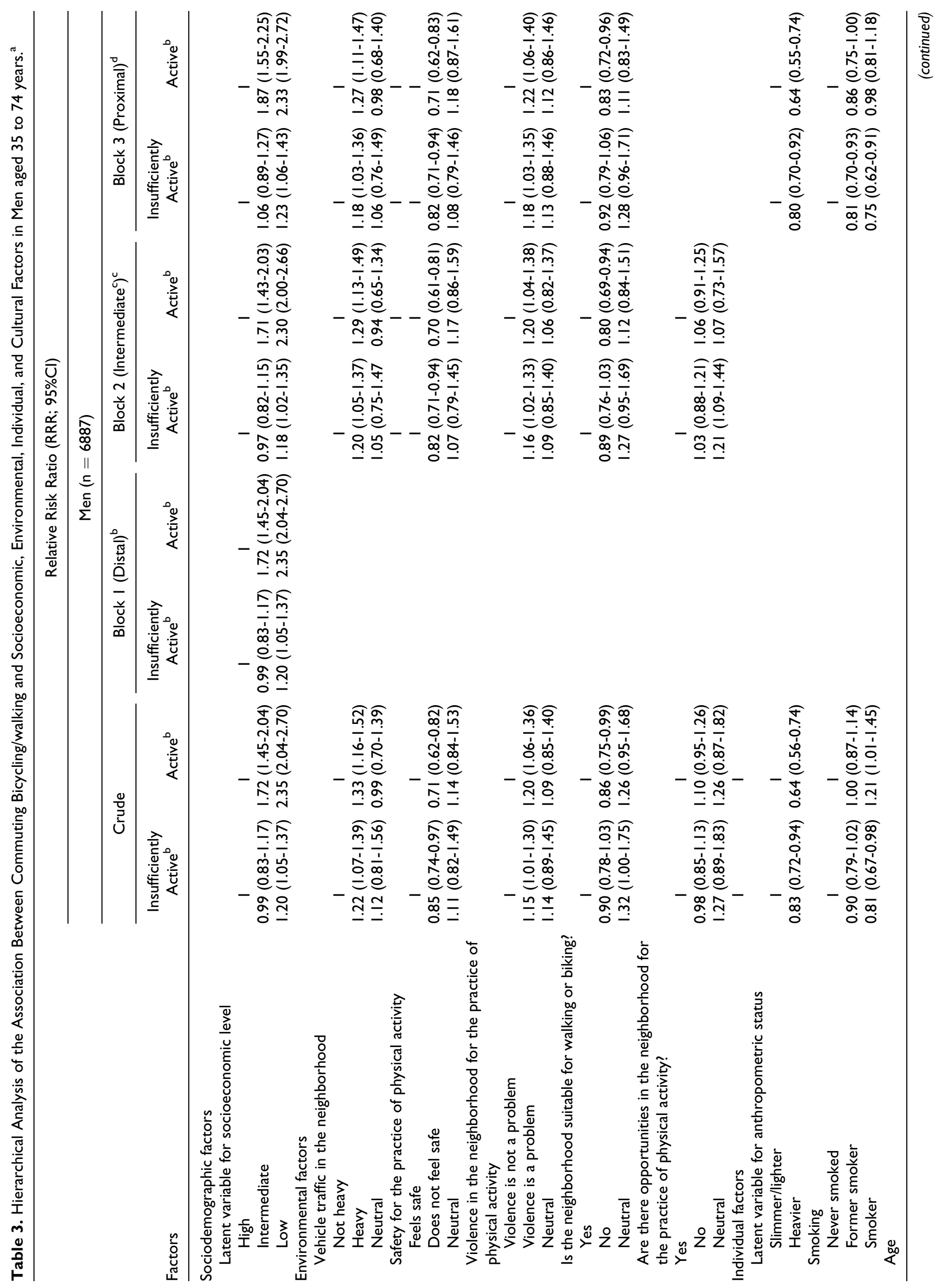




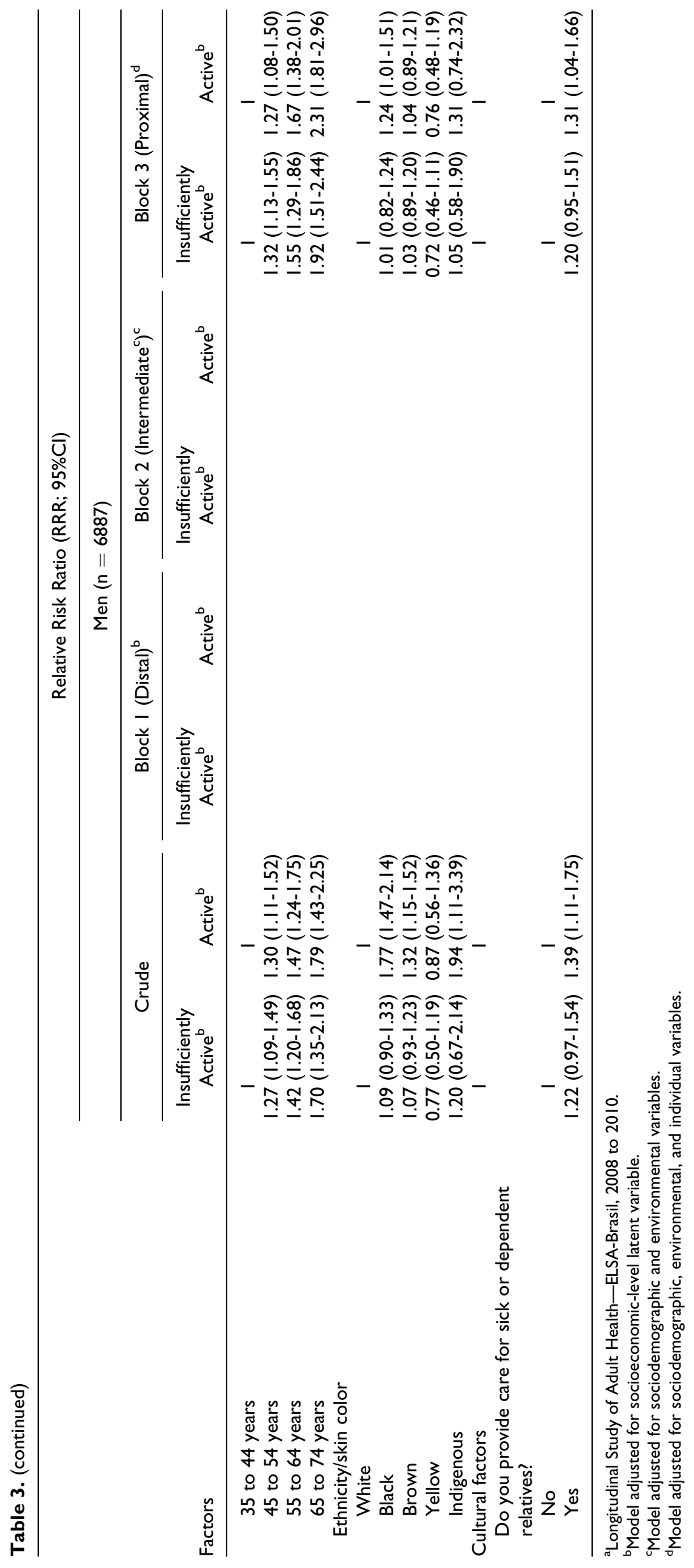


to assisting financially, ${ }^{38}$ and this paradox needs to be investigated further.

A possible limitation of the study lies in the fact that information on physical activity was obtained from self-reported questionnaires; however, these questionnaires have been widely used in national and international studies with good validity and reproducibility in Brazil. ${ }^{25}$ The ELSA-Brasil is a longitudinal study, and it is expected that more objective measures such as accelerometry will be incorporated in the future, which may increase the validity of the data on physical activity. One of the strongpoints of the study is the large sample size and the method of data production in which the participants were interviewed and examined by a supervised trained team with rigorous quality control. In addition to guaranteeing quality through the strategy of certification and re-certification of the trained supervised group to perform interviews and take measurements, the study was continuously supported by a data quality control assurance committee. ${ }^{39}$

A further limitation of the study concerns the dependent variable itself - commuting physical activity, which encompassed walking and cycling. The number of individuals participating in these 2 forms of exercise was quite different, with most individuals choosing to walk. Very few participants reported using a bicycle for commuting.

In conclusion, the principal variables that positively affected bicycling or walking as a form of commuting were poor

\section{SO WHAT? IMPLICATIONS FOR HEALTH PROMOTION PRACTITIONERS AND RESEARCHERS}

\section{What is already known on this topic?}

Different demographic, social, environmental, behavioral, and biological factors may influence the promotion of commuting by bicycling and walking.

\section{What does this article add?}

The results found in this article add to the existing literature information on the main variables demographic, social, environmental, behavioral, and biological that can influence the active displacement of populations. In this way, comparisons can be made with other national and international studies.

\section{What are the implications for health promotion practice or research?}

Formulating an explanatory model for identifying factors associated with adults who commute by bicycle or on foot in a developing country, through the use of demographic, social, environmental, behavioral, and biological determinants, is relevant and should provide subsidies for public policies of physical promotion. socioeconomic level, age, heavy traffic in the neighborhood, ethnicity/skin color, and having to care for sick or dependent family members. On the other hand, a perceived lack of safety in the neighborhood, obesity, smoking, and a lack of suitable conditions for bicycling or walking in the neighborhood were factors that negatively affected commuting physical activity.

These results may prove useful when developing policies aimed at promoting health in Brazil and in other countries with similar characteristics. These findings provide further fuel for the international debate on the adoption of healthy behaviors, introducing new evidence on the factors that influence such behaviors in a developing country marked by social inequalities in urban mobility and their association with health.

\section{Acknowledgments}

The authors wish to express their gratitude to the volunteers who participated in this study.

\section{Declaration of Conflicting Interests}

The author(s) declared no potential conflicts of interest with respect to the research, authorship, and/or publication of this article.

\section{Funding}

The author(s) disclosed receipt of the following financial support for the research, authorship, and/or publication of this article: The ELSABrasil baseline study was supported by the Brazilian Ministry of Health (Science and Technology Department) and the Brazilian Ministry of Science and Technology (Financiadora de Estudos e Projetos and CNPq National Research Council), grants 01060010.00 RS, 01 06 0212.00BA, 01060300.00 ES, 01060278.00 MG, 0106 0115.00SP, and 01060071.00 RJ. PATRÃO AL was supported by Project Attraction Young Talents, Science without Borders, CAPES, project A061/2013.

\section{Supplemental Material}

Supplementary material for this article is available online.

\section{References}

1. Hu G, Sarti C, Jousilahti P, Silventoinen K, Barengo NC, Tuomilehto J. Leisure time, occupational, and commuting physical activity and the risk of stroke. Stroke. 2005;36(9):1994-1999.

2. von Huth Smith L, Borch-Johnsen K, Jørgensen T. Commuting physical activity is favourably associated with biological risk factors for cardiovascular disease. Eur J Epidemiol. 2007; 22(11):771-779.

3. Winters M, Friesen MC, Koehoorn M, Teschke K. Utilitarian bicycling: a multilevel analysis of climate and personal influences. Am J Prev Med. 2007;32(1):52-58.

4. Titze S, Giles-Corti B, Knuiman MW, et al. Associations between intrapersonal and neighborhood environmental characteristics and cycling for transport and recreation in adults: baseline results from the RESIDE study. $J$ Phys Act Health. 2010;7(4):423-431.

5. Parra DC, Hoehner CM, Hallal PC, et al. Perceived environmental correlates of physical activity for leisure and transportation in Curitiba, Brazil. Prev Med. 2011;52(3-4):234-238. 
6. Cervero R, Sarmiento OL, Jacoby E, Gomez LF, Neiman A. Influences of built environments on walking and cycling: lessons from Bogotá. Int J Sustain Transp. 2009;3:203-226.

7. Madeira MC, Siqueira FC, Facchini LA, et al. Physical activity during commuting by adults and elderly in Brazil: prevalence and associated factors [in Portuguese]. Cad Saude Publica. 2013; 29(1):165-174.

8. Kienteka M, Reis RS, Rech CR. Personal and behavioral factors associated with bicycling in adults from Curitiba, Paraná State, Brazil. Cad Saude Publica. 2014;30(1):79-87.

9. Leslie E, Coffee N, Frank L, Owen N, Bauman A, Hugo G. Walkability of local communities: using geographic information systems to objectively assess relevant environmental attributes. Health Place. 2007;13(1):111-122.

10. Rodrigues AR, Flórez J, Frenkel DB, Portugal LS. Indicators for urban design and their relationship with the propensity to walk. $J$ Transp Lit. 2014;8(3):62-88.

11. Marquet $\mathrm{O}$, Miralles-Guasch $\mathrm{C}$. The walkable city and the importance of the proximity environments for Barcelona's everyday mobility. Cities. 2015;42(Pt B):258-266.

12. Bopp M, Kaczynski AT, Campbell ME. Health-related factors associated with mode of travel to work. J Environ Public Health. 2013;2013:242383.

13. Florindo AA, Hallal PC, Moura EC, Malta DC. Practice of physical activities and associated factors in adults, Brazil, 2006. Rev Saude Publica. 2009;43(suppl 2):65-73.

14. Silva SG, Del Duca GF, Silva KS, Oliveira ES, Nahas MV. Commuting to and from work and factors associated among industrial workers from southern Brazil. Rev Saude Publica. 2012;46(1):180-184.

15. Zanchetta LM, Barros MB, César CL, Carandina L, Goldbaum M, Alves MC. Physical inactivity and associated factors in adults, São Paulo, Brazil [in Portuguese]. Rev Bras Epidemiol. 2010; 13(3):387-399.

16. Araújo MR, Oliveira JM, Jesus MS, Sá NR, Santos PA, Lima TC. Collective public transportation: discussing accessibility, mobility and quality of life. Psicol Soc. 2011;23(3):574-582.

17. Chor D, Cardoso LO, Nobre AA, et al. Association between perceived neighbourhood characteristics, physical activity and diet quality: results of the Brazilian Longitudinal Study of Adult Health (ELSA-Brasil). BMC Public Health. 2016;16:751.

18. Christiansen LB, Cerin E, Badland H, et al. International comparisons of the associations between objective measures of the built environment and transport-related walking and cycling: IPEN. Adult Study. J Transp Health. 2016;3(4):467-478. doi: 10.1016/ j.jth.2016.02.010

19. da Silva JA, da Silva KS, Del Duca GF, et al. Moderating effect of gross family income on the association between demographic indicators and active commuting to work in Brazilian adults. Prev Med. 2016;87:51-56. doi: 10.1016/j.ypmed.2016.02.006.

20. O'Donoghue G, Perchoux C, Mensah K, et al.; DEDIPAC Consortium. A systematic review of correlates of sedentary behaviour in adults aged 18-65 years: a socio-ecological approach. BMC Public Health. 2016;16:163.

21. Aquino EM, Barreto SM, Bensenor IM, et al. Brazilian Longitudinal Study of Adult Health (ELSA-Brasil): objectives and design. Am J Epidemiol. 2012;175(4):315-324.
22. Schmidt MI, Duncan BB, Mill JG, et al. Cohort profile: Longitudinal Study of Adult Health (ELSA-Brasil). Int J Epidemiol. 2015;44(1):68-75.

23. Santos SM, Griep RH, Cardoso LO, et al. Cross-cultural adaptation and reliability of measurements on self-reported neighborhood characteristics in ELSA-Brasil [in Portuguese]. Rev Saude Publica. 2013;47(suppl 2):122-130.

24. Lohman TG, Roche AF, Martorell R. Anthropometric standardization reference manual. Champaign, IL: Human Kinetics Books; 1988:177.

25. Matsudo S, Araújo T, Matsudo V, et al. Questionário internacional de atividade física (Ipaq): estudo de validade e reprodutibilidade no Brasil . Rev Bras Atividade Fisica Saúde. 2001;6(2):5-18.

26. Dumith SC. Atividade física e sedentarismo: diferenciação e proposta de nomenclatura. Rev Bras Atividade Física Saúde. 2010; 15(4):253-254.

27. Collins LM, Lanza ST. Latent Class and Latent Transition Analysis: With Applications in the Social, Behavioral, and Health Sciences. Hoboken, NJ, USA: John Wiley \& Sons, Inc., 2010. doi:10.1002/9780470567333.

28. Akaike H. Factor analysis and AIC. Psychometrika. 1987;52(3): 317-332.

29. Schwarz G. Estimating the dimension of a model. Ann Stat. 1978; 6(2):461-464.

30. Sclove SL. Application of model-selection criteria to some problems in multivariate analysis. Psychometrika. 1987;52(3):333-343.

31. Muthén LK, Muthén BO. Mplus User's Guide. 6th ed. Los Angeles, CA: Muthén \& Muthén, 1998-2010.

32. Pitanga FJ, Matos SM, Almeida MC, Molina MC, Aquino EM. Factors associated with leisure time physical activity among ELSA-Brasil participants: ecological model. Prev Med. 2016; 90:17-25.

33. Varì R, Scazzocchio B, D'Amore A, Giovannini C, Gessani S, Masella R. Gender-related differences in lifestyle may affect health status. Ann Ist Super Sanita. 2016;52(2):158-166.

34. Griep RH, Toivanen S, van Diepen C, et al. Work-family conflict and self-rated health: the role of gender and educational level. Baseline data from the Brazilian Longitudinal Study of Adult Health (ELSA-Brasil). Int J Behav Med. 2016;23(3):372-382.

35. Whitfield GP, Paul P, Wendel AM. Active transportation surveillance-United States, 1999-2012. MMWR Surveill Summ, 2005; 64(7):1-17.

36. Benedetti T, Borges LJ, Petroski EL, Gonçalves LH. Physical activity and mental health status among elderly people [in Portuguese]. Rev Saude Publica. 2008;42(2):302-307.

37. Pitanga FG, Beck CC, Penas C, Pitanga CP, Freitas MM, Almeida LA. Prevalence and social, demographic and environmental factors associated with leisure time and commuting physical activity in adults. Motricidade. 2014;10(1):3-13.

38. Biolo HF, Portella MR. Vivência do cuidador familiar: casos acompanhados pela estratégia da saúde da família na cidade de Passo Fundo-RS. Estud Interdiscipl Envelhec. 2010;15(2): 177-195.

39. Schmidt MI, Griep RH, Passos VM, et al. Strategies and development of quality assurance and control in the ELSA-Brasil [in Portuguese]. Rev Saude Publica. 2013;47(suppl 2):105-112. 